\title{
O uso do BehavePlus como ferramenta para modelagem do comportamento e efeito do fogo
}

\author{
Benjamin Leonardo Alves White', Genésio Tâmara Ribeiro¹, Rosemeri Melo Souza1 \\ ${ }^{1}$ Universidade Federal de Sergipe, Av. Marechal Rondon, s/nº, Jardim Rosa Elze, CEP 49100-000, São Cristóvão, SE, Brasil
}

\author{
*Autor correspondente: \\ benjmk@hotmail.com \\ Termos para indexação: \\ Material combustível \\ Incêndios florestais \\ Simulação de risco de incêndio \\ Index terms: \\ Fuel load \\ Forest fire \\ Fire risk simulator
}

\section{Histórico do artigo:}

Recebido em 09/07/2012

Aprovado em 15/03/2013

Publicado em 31/03/2013

doi: 10.4336/2013.pfb.33.73.409

\begin{abstract}
Resumo - Este trabalho foi desenvolvido com o objetivo de avaliar a eficiência do software BehavePlus como ferramenta para operações de manejo do fogo em distintas vegetações ao redor do mundo. Para tal, foi realizada uma busca na literatura por trabalhos que utilizaram esta ferramenta, nos quais foram analisados os objetivos do uso, a forma em que foram utilizados, os pontos positivos, negativos e as principais questões discutidas. Através da análise das publicações, percebe-se que, apesar do software ser utilizado por um grande número de pessoas responsáveis pelo manejo do fogo nos Estados Unidos, a maioria dos trabalhos o utiliza como uma ferramenta de pesquisa e não como uma ferramenta operacional. Em função das dificuldades no processo de construção de modelos customizados e da existência de trabalhos que confirmam que nem sempre os resultados gerados pelo BehavePlus são os observados em campo, recomenda-se a adoção desta ferramenta apenas por pessoas com experiência no manejo do fogo, que são capazes de perceber quando as simulações condizem com a realidade.
\end{abstract}

\section{The use of behaveplus to model the behavior and effects of fire}

\section{Introdução}

O fogo é um elemento natural de importância fundamental na preservação e formação de alguns ecossistemas terrestres. No entanto, também é responsável por sérios danos ecológicos, materiais e financeiros, tanto em áreas de reflorestamento de monoculturas, quanto em florestas nativas.

As perdas econômicas causadas pelos incêndios florestais em áreas de plantações de espécies florestais para produção de celulose é bastante alta em todo o Brasil e ocorre todos os anos. Segundo Santos et al. (2006) entre 1998 e 2002 no Brasil, foram registrados 5.832 incêndios apenas em vegetações de Eucalyptus spp. O valor representa $30 \%$ de todos os incêndios, em todos os tipos de vegetação, registrados no Brasil. Esses incêndios responderam por uma área queimada de $13.561,65$ hectares $(16 \%$ de toda a área queimada no Brasil no período de 1998 a 2002). 
Além do aspecto econômico, o fogo tem sido apontado como um agente causador de mudanças florísticas, fitossociológicas, fisionômicas e estruturais na vegetação e na fauna, reduzindo a densidade das árvores e eliminando espécies sensíveis, tanto vegetais quanto animais. Segundo Gill (1996), o fogo pode conduzir à extinção local de espécies endêmicas, que crescem muito lentamente e sem estratégias eficientes de reprodução e colonização.

Os incêndios florestais não podem ser manejados sem uma compreensão das características básicas do combustível. É essencial a compreensão do material combustível, como pode ser manejado e manipulado para conter e controlar os incêndios, reduzir a intensidade do fogo e produzir e manter as condições desejadas nos ecossistemas naturais e nas paisagens manejadas pelo homem. O conhecimento do comportamento do fogo e sua relação com o material combustível são essenciais para a tomada efetiva de decisões sobre o manejo do fogo.

As condições climáticas também exercem influência direta na ocorrência e no modo como o fogo irá se propagar (Soares \& Batista, 2007). A intensidade de um incêndio e a velocidade com a qual ele avança estão diretamente ligadas às condições meteorológicas locais, como por exemplo, umidade relativa do ar, temperatura do ar e velocidade do vento. A utilização de dados meteorológicos precisos é, portanto, vital para o planejamento de prevenção e combate ao fogo.

O estabelecimento de cenários com base em valores reais e parâmetros estatísticos possibilitam a geração de padrões médios de carga dos combustíveis florestais que, em conjunto com valores de topografia e caracterização das condições meteorológicas, permitem estimativas sobre o provável comportamento do fogo (Beutling, 2005).

Os modelos de comportamento do fogo são geralmente compostos por equações e as suas soluções numéricas descrevem a evolução temporal e espacial de um ou mais parâmetros (Cerapiá, 2006). Dentre os diversos modelos existentes, o mais aceito e citado na literatura, é o modelo de propagação do fogo de superfície de Rothermel (1972) (Wells, 2008). Richard C. Rothermel era um engenheiro aeronáutico que trabalhava no Departamento de Agricultura Norte Americano em Missoula (Montana). Na década de 1980 seu modelo passou a ser utilizado intensamente, e, ao longo dos anos, esteve na base do desenvolvimento de diversas novas tecnologias (Wells,
2008). Até os dias atuais, suas equações são incorporadas a modernos softwares de predição do comportamento do fogo, como o BehavePlus (Andrews et al., 2003), o Farsite (Finney, 2004) e o FlamMap (Finney, 2006), que possuem a capacidade de descrever a velocidade de propagação do fogo, comprimento das chamas, energia calorífera, dentre outras características.

O uso de modelos matemáticos para prever o comportamento e o efeito do fogo constitui um passo importante no manejo dos incêndios. Quando utilizado por pessoas que possuem experiência no combate ao fogo, as previsões podem ser aplicadas com sucesso para diversas atividades relacionadas ao seu manejo, como, por exemplo, realização de queimadas controladas, determinação do perigo de ocorrência de incêndios, delineamento das áreas de maior risco, dentre outros (White, 2010).

Softwares de predição do comportamento do fogo utilizam o modelo de Rothermel em conjunto com diversos outros modelos, como o da intensidade da linha de fogo de Byram (1959), e o da probabilidade de transição para incêndio de copa de Van Wagner (1977), por exemplo. No BehavePlus existem 35 modelos matemáticos, descrito em 42 publicações, integrados à sua base de dados (Andrews, 2008). As equações não só descrevem as diversas características acerca do comportamento do fogo, como também seu efeito no ambiente, e permitem efetuar recomendações de como apagá-lo.

Em função da crescente preocupação com a preservação da biodiversidade e da proteção de áreas de reflorestamento contra o fogo, o número de trabalhos utilizando-se de softwares de predição do comportamento do fogo tem crescido inclusive no Brasil, onde até poucos anos atrás era raro encontrar publicações que utilizassem tais ferramentas. Portanto, este estudo tem como objetivo fazer um levantamento das vantagens, desvantagens e possibilidades de uso do BehavePlus, software de previsão do comportamento do fogo mais utilizado no mundo (Andrews, 2010), com base nos trabalhos publicados, para que assim seja possível assessorar e gerar recomendações para pesquisadores ou pessoas envolvidas no manejo do fogo que utilizem ou que tenham interesse em utilizar esta ferramenta.

\section{O Behave e o BehavePlus}

Predizer o potencial de destruição de um incêndio e seus efeitos sobre a vida selvagem é uma tarefa essencial. Diferentes tipos de sistemas são usados para se estudar o fogo, entretanto um dos mais importantes é o "Behave: fire behavior prediction system", em substituição pelo 
BehavePlus (Van Wagtendonk, 1996). Segundo Barret et al. (2000) este sistema é utilizado por cerca de $85 \%$ dos gestores de fogo prescrito no oeste dos Estados Unidos.

No sistema Behave e BehavePlus, as características do material combustível, da umidade do material combustível, do vento e do declive do terreno são assumidas como constantes durante o período em que as predições estão sendo aplicadas. Devido ao fato de que os incêndios ocorrem sempre em condições não uniformes, a duração do período de projeção e a escolha do material combustível necessitam ser tomadas com muita precaução. Para condições mais uniformes as predições podem ser utilizadas por mais tempo. Quando o fogo avança de um tipo de vegetação para outro, como por exemplo, de um campo graminoso para liteira de uma floresta, o tipo do material combustível, assim como sua umidade, a inclinação do terreno e a velocidade do vento devem ser ajustados para esta nova condição (Andrews, 1986).

A capacidade do BehavePlus em modelar o comportamento do fogo está agrupada em módulos
(Tabela 1). O termo modelo se refere às relações matemáticas que descrevem um aspecto específico do fogo, como velocidade de propagação, altura de crestamento da copa das árvores, fator de ajuste da velocidade do vento, dentre outros (Andrews \& Queen, 2001).

\section{Variáveis de Entrada}

O primeiro problema que surge quando se pretende simular o comportamento do fogo é a obtenção dos valores de entrada do modelo (inputs) para as condições de material combustível, relevo e meteorologia, no qual o fogo irá se propagar. Um exemplo é dado na Tabela 2, na qual estão descritas as variáveis de entrada necessárias para calcular as características de um fogo superficial (módulo superfície), no qual é definido como um fogo que se propaga nos estratos de combustível até $1,8 \mathrm{~m}$ de altura (Andrews, 2009).

Um grupo de parâmetros de entrada que requer especial atenção e trabalho é o que caracteriza o material combustível em função da sua heterogeneidade e irregularidade na distribuição espacial das partículas.

Tabela 1. Cálculos realizados pelo BehavePlus de acordo com o módulo (Fonte: Andrews, 2009).

\begin{tabular}{|c|c|}
\hline Módulo & Cálculo \\
\hline Superfície & $\begin{array}{l}\text { - Velocidade de propagação do fogo superficial; } \\
\text { - Intensidade da linha do fogo e comprimento das chamas; } \\
\text { - Intensidade de reação e energia calorífera por unidade de área; } \\
\text { - Modelos de combustível: padrão, customizados e casos especiais; } \\
\text { - Fator de ajuste da velocidade do vento. }\end{array}$ \\
\hline Copa & $\begin{array}{l}\text { - Transição de incêndio superficial para incêndio de copa; } \\
\text { - Velocidade de propagação do incêndio de copa; } \\
\text { - Área e perímetro; } \\
\text { - Tipo de incêndio; } \\
\text { - Intensidade e comprimento das chamas. }\end{array}$ \\
\hline Segurança & $\begin{array}{l}\text { - Tamanho da área de segurança baseado no comprimento das chamas; } \\
\text { - Área, perímetro e distância de segurança. }\end{array}$ \\
\hline Tamanho & $\begin{array}{l}\text { - Modelo elíptico; } \\
\text { - Área, perímetro e forma. }\end{array}$ \\
\hline Controle & $\begin{array}{l}\text { - Sucesso do controle do fogo através de um único ou múltiplos recursos com base no tempo de } \\
\text { resposta, tipo de ataque ao fogo, duração dos recursos; } \\
\text { - Área e perímetro da área consumida pelo fogo, tamanho do fogo durante o ataque inicial. }\end{array}$ \\
\hline Projeções & - Distância máxima que um incêndio pode gerar novos focos através de fagulhas carregadas pelo vento. \\
\hline Altura & - Altura de crestamento da copa com base no comprimento da chama do fogo de superfície. \\
\hline Mortalidade & - Probabilidade de mortalidade da árvore com base na espessura da casca e na altura de crestamento da copa. \\
\hline Ignição & - Probabilidade de ignição através de fagulhas ou através de raios. \\
\hline
\end{tabular}


Tabela 2 . Variáveis de entrada necessárias para simular o comportamento da frente do fogo em um incêndio superficial utilizando o BehavePlus (Fonte: Andrews, 2009).

\begin{tabular}{|c|c|}
\hline \multirow{15}{*}{$\begin{array}{l}\text { Variáveis de caracterização do } \\
\text { combustível superficial }\end{array}$} & Variáveis de Entrada (inputs) \\
\hline & Modelo do combustível; \\
\hline & Tipo do modelo do combustível; \\
\hline & Carga do combustível de 1-h de timelag $\left(\mathrm{t} \mathrm{ha}^{-1}\right)$; \\
\hline & Carga do combustível de $10-\mathrm{h}$ de timelag $\left(\mathrm{t} \mathrm{ha}^{-1}\right)$; \\
\hline & Carga do combustível de 100-h de timelag $\left(\mathrm{t} \mathrm{ha}^{-1}\right)$; \\
\hline & Carga do combustível vivo herbáceo $\left(\mathrm{t} \mathrm{ha}^{-1}\right)$; \\
\hline & Carga do combustível vivo lenhoso $\left(\mathrm{t} \mathrm{ha}^{-1}\right)$; \\
\hline & Área superficial pelo volume do combustível de 1-h de timelag $\left(\mathrm{m}^{2} \mathrm{~m}^{-3}\right)$; \\
\hline & Área superficial pelo volume do combustível vivo herbáceo $\left(\mathrm{m}^{2} \mathrm{~m}^{-3}\right)$; \\
\hline & Área superficial pelo volume do combustível vivo lenhoso $\left(\mathrm{m}^{2} \mathrm{~m}^{-3}\right)$; \\
\hline & Espessura do leito (m); \\
\hline & Umidade de extinção do combustível morto (\%); \\
\hline & Energia calorífera do combustível morto $\left(\mathrm{kJ} \mathrm{kg}^{-1}\right)$; \\
\hline & Energia calorífera do combustível vivo $\left(\mathrm{kJ} \mathrm{kg}^{-1}\right)$. \\
\hline \multirow{5}{*}{$\begin{array}{l}\text { Variáveis de caracterização do } \\
\text { teor de umidade do material } \\
\text { combustível superficial }\end{array}$} & Umidade do combustível morto $1-\mathrm{h}$ de timelag (\%); \\
\hline & Umidade do combustível morto 10 -h de timelag (\%); \\
\hline & Umidade do combustível morto 100 -h de timelag $(\%)$; \\
\hline & Umidade do combustível vivo herbáceo; \\
\hline & Umidade do combustível vivo lenhoso. \\
\hline Variável de caracterização do clima & Velocidade do vento a meia altura da chama $\left(\mathrm{km} \mathrm{h}^{-1}\right)$. \\
\hline Variável de caracterização do relevo & Declive do terreno $(\%)$. \\
\hline
\end{tabular}

Na base de dados do BehavePlus existem 56 modelos padrões de combustível superficial descritos por Scott \& Burgan (2005). A opção por um modelo padrão poupa tempo e esforço do pesquisador, já que é necessário muito trabalho de campo para descrever tais valores. Entretanto, deve-se levar em conta, que os modelos existentes foram criados com o objetivo de caracterizar as principais formações vegetacionais encontradas nos Estados Unidos. Em função das características peculiares existentes em fitofisionomias encontradas nas diferentes regiões do globo, diversos autores (Burgan 1987; Grabner et al., 1997; White, 2010; Keane, 2012) recomendam que, para realizar uma eficiente simulação do comportamento do fogo, o pesquisador opte por utilizar modelos customizados do material combustível, que são construídos a partir da obtenção de valores estatísticos médios dos parâmetros que representam o material combustível local. Tal medição constitui um passo trabalhoso, mas essencial no processo de modelagem do comportamento do fogo.
Em face das dificuldades mencionadas, um procedimento comum usado na construção de um modelo de combustível consiste em determinar empiricamente alguns dos seus parâmetros, de modo a ajustar as previsões do modelo de propagação aos valores experimentais, medidos em testes auxiliares simples realizados na vegetação em questão. Naturalmente que tal procedimento retira, em maior ou menor medida, o valor de validação. Por outro lado, o fato de se identificarem padrões de vegetação mais ou menos regulares nos ecossistemas, permite a construção de um catálogo de modelos de combustível, de modo a permitir, posteriormente, um reconhecimento do modelo de combustível mais adequado para representar uma dada vegetação, por simples comparação visual (André \& Viegas, 2002).

Outra questão importante que se coloca dentro do problema mais amplo da determinação dos parâmetros de entrada do modelo de propagação é a necessidade 
de estimar parâmetros dinâmicos, como por exemplo, a velocidade do vento ou o teor de umidade dos vários tipos de partículas que compõem o material combustível. A estimativa de valores médios é bem complicada e muitas vezes são medidos erroneamente pelos pesquisadores. André \& Viegas (2002) citam que a velocidade do vento próximo à frente de fogo é particularmente complexa, pois pode envolver, no caso mais geral, modelos de predição relativamente diferenciados, em quatro grandes escalas espaciais, a saber: a sinóptica (da circulação atmosférica geral), a mesoescala (apenas sensível aos grandes acidentes de terreno), a da topografia mais complexa e a da vegetação.

É necessária uma análise climática completa para que seja possível estimar valores médios da velocidade do vento para o período no qual costumam ocorrer incêndios. White (2010), por exemplo, utilizou uma base de dados de 24.916 registros da velocidade do vento, medida a cada 30 minutos durante a estação seca, para determinar um valor médio da velocidade do vento para a sua área de estudo.

Já para se determinar o teor de umidade do material combustível o procedimento é um pouco mais complicado. Existe uma metodologia direta, na qual o material combustível é coletado, pesado, levado para estufa, e pesado novamente para se determinar o peso seco e o teor de umidade. Entretanto, tal valor vai responder pelo teor de umidade deste material na hora e no dia em que o mesmo foi coletado, já que tais materiais podem alterar seus valores em questão de horas ou dias a depender das condições meteorológicas (Rothermel 1972, Soares \& Batista, 2007). Existem modelos matemáticos, como por exemplo o FWI (Fire Weather Index) desenvolvido pelo Serviço Canadense de Florestas que é utilizado por vários países no mundo, em particular na Europa; o Norte Americano NFDRS (National Fire Danger Rating System); o modelo Australiano de McArthur (1962), dentre outros, no qual, com base nos valores diários de variáveis meteorológicas, como: temperatura, umidade relativa do ar e precipitação, é possível estimar o teor de umidade dos materiais combustíveis mortos e consequentemente indicar o perigo de ocorrência de incêndio. Cada modelo irá responder por um tipo de vegetação localizada dentro de um determinado padrão climático, já que não costumam responder com eficiência em situações que o clima e as características do material combustível são distintas dos ambientes para qual foram desenvolvidas.
Portanto, antes de se fazer um estudo é necessário definir se os modelos existentes respondem corretamente, ou se será necessário desenvolver um novo modelo da umidade do material combustível para a área de estudo em questão.

\section{Análise das publicações}

Devido às dificuldades e problemas envolvendo a obtenção das variáveis de entrada do BehavePlus e do fato de ser um programa recente (primeira versão criada em 2002), não é muito comum encontrar na literatura trabalhos utilizando esta ferramenta. A grande maioria dos estudos são realizados em países como Estados Unidos, Portugal e algumas outras regiões da Europa ocidental, sendo muito pequena a quantidade de trabalhos realizados no Brasil.

De acordo com a metodologia empregada, os estudos podem ser classificados em de simulação, ou de simulação e validação. Além desta classificação, os mesmos ainda podem ser separados em função do módulo utilizado no BehavePlus (Tabela 1).

Estudos baseados apenas em simulações são mais simples e mais fáceis de serem realizados, entretanto, não concluem experimentalmente se os resultados obtidos são similares ou não aos incêndios reais. Mohr et al. (2004), por exemplo, utilizaram o BehavePlus para verificar a eficiência de procedimentos de redução de biomassa como queimadas prescritas e derrubada de árvores, na redução do potencial de incêndios florestais. Apenas baseando-se nos resultados simulados, os autores concluíram que incêndios prescritos, com o objetivo de reduzir a quantidade de material combustível, é um método eficiente para reduzir o perigo de ocorrência de incêndios florestais na floresta de Clemson, no nordeste da Carolina do Sul. Em outro estudo similar, Morh et al. (2010) utilizaram o BehavePlus para simular o comportamento do fogo em vegetações submetidas a distintos tratamentos de redução do material combustível, em Polk County, Flórida, no qual concluíram que nas áreas submetidas apenas ao desbaste, o fogo teve as chamas mais altas e com maior velocidade de propagação, enquanto que nas áreas submetidas ao desbaste e posterior queima controlada, o fogo simulado teve menor intensidade. Ainda com o objetivo de avaliar o comportamento do fogo frente às técnicas de redução do material combustível, Vollmer (2005) utilizou o BehavePlus para simular o comportamento da frente do fogo antes e depois da utilização de herbicidas para reduzir a quantidade de gramíneas em ambientes de 
interface urbana/selvagem com alto risco de ocorrência de incêndios no estado de Idaho, nos Estados Unidos. Segundo o autor, as simulações sugerem que quando ocorre a utilização de herbicidas para controlar o crescimento de gramíneas, o comprimento das chamas pode ser reduzido em até $90 \%$.

Dentre os trabalhos de simulação que utilizaram o BehavePlus no Brasil, podemos citar White (2010) no Parque Nacional Serra de Itabaiana, no estado de Sergipe, que estabeleceu o comportamento do fogo dentro de distintas formações vegetais, com o objetivo de delimitar áreas de maior risco e fornecer dados importantes para auxílio das ações de combate ao fogo; Mistry \& Berardi (2005), que avaliaram o potencial do dano pelo fogo em vegetação de cerrado em uma unidade de conservação no Planalto Central do Brasil; e Hoffmann et al. (2012) que parametrizam o comportamento do fogo em áreas de cerrado e floresta no sul e centro do Brasil.

Ainda, comentando sobre trabalhos apenas de simulação, é importante citar Dimitrakopoulos (2002), que utilizou o Behave em um amplo trabalho para descrever o provável comportamento do fogo dentro de 181 distintas formações vegetais encontradas na Grécia.

Esses trabalhos de simulação (Tabela 3), constituem os mais comuns tipos de estudos utilizando o BehavePlus, no qual, com base nas características da vegetação, clima e relevo locais, são simuladas as características de um potencial incêndio ou queima controlada com o objetivo de delimitação de áreas de maior risco ou desenvolvimento de programas de queima controlada. Embora tais estudos tenham sua importância, Rothermel \& Rinehard (1983) e Burgan \& Rothermel (1984) afirmam que para verificar se os resultados simulados estão condizentes com a realidade, é necessário comparar os mesmos com situações reais. Entretanto, no geral, os pesquisadores ignoram ou apenas parcialmente aplicam tal procedimento. É comum os autores utilizarem dados da literatura para detectar possíveis resultados irrelevantes, além de conselhos de especialistas em comportamento do fogo para discutir os resultados. De certa forma, a falta de dados empíricos do comportamento do fogo obtidos através de incêndios reais ou queimadas controladas, acaba por dificultar a validação destas simulações.

Tabela 3. Trabalhos de simulação encontrados na literatura que utilizaram o módulo "Superfície” do BehavePlus com o objetivo de modelagem do comportamento do fogo.

\begin{tabular}{|c|c|c|c|c|}
\hline Local & $\begin{array}{c}\text { Modelo do } \\
\text { material } \\
\text { combinado }\end{array}$ & Tipo de vegetação & Finalidade do uso do BehavePlus & Referência \\
\hline $\begin{array}{l}\text { Carolina do Sul, } \\
\text { Estados Unidos }\end{array}$ & $\begin{array}{c}\text { Modelo } \\
\text { customizado }\end{array}$ & $\begin{array}{c}\text { Pinheiro (Pinus taeda L. e } P . \\
\text { echinata Mill.) }\end{array}$ & $\begin{array}{l}\text { Simular a eficiência de metodologias } \\
\text { de redução do material combustível } \\
\text { na redução da intensidade do fogo }\end{array}$ & Mohr et al. (2004) \\
\hline $\begin{array}{c}\text { Flórida, Estados } \\
\text { Unidos }\end{array}$ & $\begin{array}{c}\text { Modelo } \\
\text { customizado }\end{array}$ & $\begin{array}{c}\text { Pinheiros e vegetação arbustiva } \\
\text { formada pelas espécies Kalmia } \\
\text { latifolia, Rhododendron spp., e } \\
\text { Vaccinium spp. }\end{array}$ & $\begin{array}{l}\text { Simular a eficiência de metodologias } \\
\text { de redução do material combustível } \\
\text { na redução da intensidade do fogo }\end{array}$ & Mohr et al. (2010) \\
\hline $\begin{array}{l}\text { Idaho, Estados } \\
\text { Unidos }\end{array}$ & $\begin{array}{c}\text { Modelo } \\
\text { customizado }\end{array}$ & $\begin{array}{c}\text { Gramíneas anuais e arbustivas } \\
\text { perenes }\end{array}$ & $\begin{array}{l}\text { Simular a eficiência da utilização de } \\
\text { herbicidas na redução da intensidade } \\
\text { do fogo }\end{array}$ & Vollmer (2005) \\
\hline Sergipe, Brasil & $\begin{array}{c}\text { Modelo } \\
\text { customizado }\end{array}$ & $\begin{array}{l}\text { Gramíneas anuais; floresta tropical } \\
\text { secundária; vegetação arbustiva }\end{array}$ & $\begin{array}{c}\text { Simular o comportamento do fogo e } \\
\text { delinear áreas de risco }\end{array}$ & White (2010) \\
\hline $\begin{array}{l}\text { Planalto Central, } \\
\text { Brasil }\end{array}$ & $\begin{array}{l}\text { Modelo } \\
\text { customizado }\end{array}$ & Cerrado & $\begin{array}{l}\text { Simular o comportamento do fogo e } \\
\text { avaliar o seu potencial de dano }\end{array}$ & $\begin{array}{l}\text { Mistry \& Berardi } \\
(2005)\end{array}$ \\
\hline $\begin{array}{l}\text { Sul e centro, } \\
\text { Brasil }\end{array}$ & $\begin{array}{c}\text { Modelo } \\
\text { customizado }\end{array}$ & Interface: cerrado - floresta & $\begin{array}{l}\text { Simular a diferença no } \\
\text { comportamento do fogo em áreas de } \\
\text { cerrado e floresta }\end{array}$ & $\begin{array}{l}\text { Hoffmann et al. } \\
\qquad(2012)\end{array}$ \\
\hline Grécia & $\begin{array}{l}\text { Modelo } \\
\text { customizado }\end{array}$ & 181 distintas formações vegetais & $\begin{array}{l}\text { Simular o comportamento do fogo } \\
\text { em distintas formações vegetais } \\
\text { encontradas na Grécia }\end{array}$ & $\begin{array}{c}\text { Dimitrakopoulos } \\
\text { (2002) }\end{array}$ \\
\hline
\end{tabular}


Já estudos de simulação e validação são mais complexos de serem realizados e apresentam uma maior importância científica, já que, além de simular, provam experimentalmente se as simulações são ou não condizentes com a realidade. Em Portugal, Fernandes (2002), por exemplo, realizou queimadas superficiais controladas em povoamentos de Pinus pinaster Ait. e comparou os resultados obtidos no campo com os resultados simulados pelo BehavePlus. Suas conclusões sugerem que o software gera predições da velocidade de propagação do fogo imprecisas e pouco correlacionadas com as observações em campo, que, quase sempre, foram subavaliadas pelas simulações. Fernandes (2009), também em plantações de Pinus pinaster em Portugal, novamente obteve simulações da velocidade de propagação do fogo e da altura das chamas menores do que as observadas através de queimadas experimentais. A velocidade de propagação do fogo simulado chegou a ser $22 \%$ menor do que a observada, enquanto que o comprimento simulado das chamas chegou a ser $48 \%$ menor do que o valor observado experimentalmente.

Um outro importante trabalho que realizou comparação dos dados simulados com os dados obtidos através de queimadas experimentais foi realizado por Stephens et al. (2008). Segundo os autores, os resultados da velocidade de propagação do fogo e do comprimento das chamas, em vegetações predominantemente arbustivas da espécie Adenostoma fasciculatum, no norte da Califórnia, também foram subavaliados pelo BehavePlus. As simulações da velocidade de propagação apresentaram valores entre $50 \%$ a $75 \%$ dos valores experimentais, enquanto que os valores do comprimento das chamas estiveram entre $27 \%$ a $73 \%$ dos valores obtidos durante os experimentos em campo.

Nos três trabalhos supracitados, os autores reconhecem a utilidade indiscutível do BehavePlus em relação a aplicações relacionadas com a pré-supressão de incêndios, entretanto, afirmam que o mesmo é insuficiente para utilização operacional no fogo controlado. De acordo com os autores, o sistema Behave é útil para planejar um fogo prescrito de modo a que não ofereça dificuldades de contenção, nem danifique o estrato arbóreo, mas é incapaz de informar quanto ao cumprimento dos objetivos da queimada, ou predizer outros efeitos do fogo.

Cruz \& Fernandes (2008) realizaram o procedimento contrário, ou seja, a partir de queimadas experimentais em floresta de Pinus pinaster em Portugal. Os autores desenvolveram um modelo customizado do material combustível no qual as simulações geradas pelo BehavePlus correspondessem aos dados obtidos em campo. O modelo construído não representou necessariamente as características do material combustível coletado na área de estudo. Os autores justificam que a construção de modelos customizados de liteira podem subestimar a velocidade de propagação do fogo em função, principalmente, da dificuldade que existe em quantificar a fração e a taxa de compactação da camada da liteira que está conduzindo o fogo, indicando com isso a necessidade da realização de queimadas experimentais.

O problema está no fato de que os modelos construídos em laboratório, como, por exemplo, o modelo de Rothermel (1972), são desenvolvidos e calibrados em condições homogêneas de material combustível. Portanto, há de se esperar que os valores médios utilizados para construir modelos customizados de combustíveis nem sempre devam responder com fidelidade em situações reais, já que, em incêndios naturais, o material combustível costuma ser bastante heterogêneo, especialmente com relação à carga e à espessura do leito, variáveis que influenciam bastante as características do fogo no modelo de propagação de Rothermel (1972). Gould (1991); Andrews (2009), Cruz \& Fernandes (2008) e Glitzenstein (2006), por exemplo, afirmam que a maior dificuldade na utilização do modelo de Rothermel (1972) é a obtenção de um valor apropriado da espessura do leito do material combustível, já que o modelo é bastante sensível para tal característica.

Ainda assim, não são todos os estudos de simulação e validação que tiveram seus resultados subavaliados. Van Wagtendonk \& Botti (1984) testaram o modelo de propagação de fogo de superfície de Rothermel (1972) em seis distintas vegetações no Parque Nacional de Yosemite, na California, Estados Unidos, e definiram que as simulações superstimaram, em pequena escala, os valores experimentais. Glitzenstein (2006) definiu, através de queimadas experimentais, que as simulações realizadas pelo BehavePlus previram corretamente incêndios de baixa intensidade e de baixa velocidade de propagação em oito parcelas localizadas na Floresta Nacional Francis Marion, no estado da Carolina do Sul, Estados Unidos. Resultados positivos do modelo de propagação do fogo de superfície de Rothermel (1972) também foram descritos por Hough \& Albine (1978) (Tabela 4). 
Tabela 4. Descrição dos trabalhos de simulação e validação encontrados na literatura que utilizaram o modelo de Rothermel (1972) integrado ao módulo "superfície" no BehavePlus com o objetivo de modelagem do comportamento do fogo.

\begin{tabular}{|c|c|c|c|c|c|}
\hline Local & $\begin{array}{c}\text { Tipo de } \\
\text { vegetação }\end{array}$ & Finalidade do uso do BehavePlus & $\begin{array}{c}\text { Modelo do } \\
\text { combustível }\end{array}$ & $\begin{array}{c}\text { Simulações } \\
\text { satisfatórias? }\end{array}$ & Referência \\
\hline $\begin{array}{l}\text { Sevivas, } \\
\text { Portugal }\end{array}$ & $\begin{array}{l}\text { Pinheiro (Pinus } \\
\text { pinaster) }\end{array}$ & $\begin{array}{l}\text { Verificar a eficiência das simulações } \\
\text { do BehavePlus na modelagem do fogo } \\
\text { superficial }\end{array}$ & $\begin{array}{l}\text { Modelo } \\
\text { customizado }\end{array}$ & $\begin{array}{l}\text { Não. Comprimento das } \\
\text { chamas e velocidade de } \\
\text { propagação subavaliadas }\end{array}$ & $\begin{array}{l}\text { Fernandes } \\
\quad(2002)\end{array}$ \\
\hline $\begin{array}{l}\text { Sevivas, } \\
\text { Portugal }\end{array}$ & $\begin{array}{l}\text { Pinheiro (Pinus } \\
\text { pinaster) }\end{array}$ & $\begin{array}{l}\text { Verificar a eficiência das simulações } \\
\text { do BehavePlus na modelagem do fogo } \\
\text { superficial }\end{array}$ & $\begin{array}{c}\text { Modelo } \\
\text { customizado }\end{array}$ & $\begin{array}{l}\text { Não. Comprimento das } \\
\text { chamas e velocidade de } \\
\text { propagação subavaliadas }\end{array}$ & $\begin{array}{l}\text { Fernandes } \\
\quad(2009)\end{array}$ \\
\hline $\begin{array}{l}\text { Califórnia, } \\
\text { Estados } \\
\text { Unidos }\end{array}$ & $\begin{array}{l}\text { Adenostoma } \\
\text { fasciculatum }\end{array}$ & $\begin{array}{l}\text { Comparar os dados obtidos em campo } \\
\text { com as simulações do BehavePlus }\end{array}$ & $\begin{array}{l}\text { NFFL 4, } \\
\text { SH5, SH7, } \\
\text { SCAL15, } \\
\text { SCAL17 }\end{array}$ & $\begin{array}{l}\text { Não. Comprimento das } \\
\text { chamas e velocidade de } \\
\text { propagação subavaliadas }\end{array}$ & $\begin{array}{l}\text { Stephens et } \\
\text { al. (2008) }\end{array}$ \\
\hline $\begin{array}{c}\text { Yosemite } \\
\text { National } \\
\text { Park, } \\
\text { California, } \\
\text { Estados } \\
\text { Unidos }\end{array}$ & $\begin{array}{l}\text { Seis distintas } \\
\text { formações } \\
\text { vegetais }\end{array}$ & $\begin{array}{c}\text { Testar o modelo de propagação de } \\
\text { Rothermel (1972) com dados de } \\
\text { queimadas controladas }\end{array}$ & $\begin{array}{c}\text { Modelo } \\
\text { customizado }\end{array}$ & $\begin{array}{l}\text { Sim. Pequenas diferenças } \\
\text { na velocidade de } \\
\text { propagação na ordem de } \\
0,9 \mathrm{~cm} \mathrm{~min}^{-1}\end{array}$ & $\begin{array}{l}\text { Van } \\
\text { Wagtendonk } \\
\text { \& Botti } \\
(1984)\end{array}$ \\
\hline $\begin{array}{l}\text { Região } \\
\text { sul dos } \\
\text { Estados } \\
\text { Unidos }\end{array}$ & $\begin{array}{l}\text { Serenoa repens } \\
\text { e Ilex glabra }\end{array}$ & $\begin{array}{c}\text { Comparar os dados experimentais com } \\
\text { as simulações utilizando o modelo de } \\
\text { Rothermel (1972) }\end{array}$ & $\begin{array}{c}\text { Modelo } \\
\text { customizado }\end{array}$ & $\begin{array}{l}\text { Sim. A discrepância } \\
\text { não foi considerada } \\
\text { grande o suficiente } \\
\text { para desqualificar as } \\
\text { simulações }\end{array}$ & $\begin{array}{l}\text { Hough \& } \\
\text { Albine } \\
\text { (1978) }\end{array}$ \\
\hline $\begin{array}{l}\text { Carolina } \\
\text { do Sul, } \\
\text { Estados } \\
\text { Unidos }\end{array}$ & $\begin{array}{l}\text { Vegetação } \\
\text { de interface } \\
\text { urbana - } \\
\text { florestal. }\end{array}$ & $\begin{array}{l}\text { Avaliar a eficiência do BehavePlus na } \\
\text { simulação do comportamento do fogo }\end{array}$ & $\begin{array}{c}\text { Modelo } \\
\text { customizado }\end{array}$ & Sim & $\begin{array}{l}\text { Glitzensteina } \\
\text { et al. (2006) }\end{array}$ \\
\hline
\end{tabular}

Apesar da maioria dos estudos utilizando o BehavePlus utilizarem apenas o módulo "superfície", é importante comentar outros trabalhos como o de Hood et al. (2007), por exemplo, que realizaram um estudo de simulação e validação utilizando o módulo "Mortalidade" para determinar a taxa de mortalidade pós-fogo de 13 espécies de árvores coníferas nos estados de Arizona, Califórnia, Idaho, Montana e Wyoming, Estados Unidos (Tabela 5). Segundo os autores, a fidelidade dos resultados obtidos através das simulações com o BehavePlus, com relação à quantidade de árvores mortas pós-fogo, variou conforme a espécie em questão, sendo que, em determinados casos, a taxa de mortalidade observada foi a mesma que a taxa de mortalidade prevista (100\% de acerto). Entretanto, na maioria das situações, a taxa de mortalidade prevista pelo BehavePlus costumou ser maior do que a observada experimentalmente. Contudo, no geral, os autores chegaram à conclusão de que o modelo de mortalidade de Ryan \& Amman (1994), utilizado pelo BehavePlus, é eficiente na previsão da mortalidade de diversas espécies.

Dentre outros estudos que utilizaram diferentes módulos, pode-se citarCurt \& Delcros (2007) que utilizaram o módulo "ignição" do BehavePlus e estabeleceram a probabilidade de ignição nas beiras das estradas no sudeste da França; e Cruz \& Alexander (2010) que utilizaram o módulo "copa" para definir a eficiência do modelo em descrever o comportamento do incêndio de copa. O primeiro é apenas um estudo de simulação, portanto não foi validado, já no segundo, os autores chegaram à conclusão que o modelo utilizado pelo BehavePlus subestima significativamente o comportamento de um incêndio de copa real.

Por fim, basta comentar que embora na base de dados do BehavePlus constem apenas 53 modelos padrões de materiais combustíveis (Scoot \& Burgan, 2005), existem diversos trabalhos na literatura nos quais são construídos modelos customizados para realizar 
simulações. Diamond et al. (2009), por exemplo, utilizam os dados coletados em campo com o objetivo de desenvolver um modelo para gramíneas de clima seco encontradas em Nevada, Estados Unidos. White (2010), também utiliza os dados de coleta em campo, para desenvolver três modelos de material combustível para as distintas formações vegetais encontradas no Parque Nacional Serra de Itabaiana. É de suma importância que novos modelos de combustível desenvolvidos por pesquisadores venham a ser inseridos na base de dados do software, a fim de que o mesmo possa ser utilizado em uma maior variedade de vegetações.

Tabela 5. Descrição dos trabalhos encontrados na literatura que utilizaram diferentes módulos do BehavePlus, fora o "Superfície", com o objetivo de modelar o comportamento do fogo e avaliar os seus efeitos.

\begin{tabular}{|c|c|c|c|c|c|c|}
\hline Local & $\begin{array}{l}\text { Classificação } \\
\text { do estudo }\end{array}$ & Módulo & $\begin{array}{c}\text { Tipo de } \\
\text { vegetação }\end{array}$ & $\begin{array}{l}\text { Finalidade do uso } \\
\text { do BehavePlus }\end{array}$ & Simulações satisfatórias? & Referência \\
\hline $\begin{array}{l}\text { Arizona, } \\
\text { Califórnia, } \\
\text { Estados } \\
\text { Unidos }\end{array}$ & $\begin{array}{l}\text { Simulação e } \\
\text { Validação }\end{array}$ & Mortalidade & $\begin{array}{l}13 \text { espécies de } \\
\text { Coníferas }\end{array}$ & $\begin{array}{l}\text { Avaliar a eficácia } \\
\text { na previsão da } \\
\text { mortalidade de } \\
\text { coníferas pelo } \\
\text { BehavePlus }\end{array}$ & $\begin{array}{c}\text { A depender da espécie. } \mathrm{Na} \\
\text { maioria dos casos a taxa } \\
\text { de mortalidade prevista } \\
\text { costumou ser maior do } \\
\text { que a observada }\end{array}$ & $\begin{array}{l}\text { Hood et al. } \\
\text { (2007) }\end{array}$ \\
\hline $\begin{array}{l}\text { Aix-en- } \\
\text { Provence, } \\
\text { França }\end{array}$ & Simulação & Ignição & $\begin{array}{l}\text { Vegetação } \\
\text { formada por } \\
\text { gramíneas, } \\
\text { liteira e arbustos }\end{array}$ & $\begin{array}{c}\text { Simular a } \\
\text { probabilidade de } \\
\text { ignição do material } \\
\text { combustível }\end{array}$ & - & $\begin{array}{l}\text { Curt \& } \\
\text { Delcros } \\
(2007)\end{array}$ \\
\hline $\begin{array}{c}\text { Região } \\
\text { ocidental da } \\
\text { América do } \\
\text { Norte }\end{array}$ & $\begin{array}{l}\text { Simulação e } \\
\text { Validação }\end{array}$ & Copa & $\begin{array}{l}\text { Floresta de } \\
\text { coníferas }\end{array}$ & $\begin{array}{c}\text { Verificar a } \\
\text { eficiência do } \\
\text { BehavePlus } \\
\text { em descrever } \\
\text { incêndios de copa }\end{array}$ & $\begin{array}{c}\text { Não. Simulações } \\
\text { subestimam } \\
\text { significativamente o } \\
\text { comportamento de um } \\
\text { incêndio de copa real }\end{array}$ & $\begin{array}{l}\text { Cruz \& } \\
\text { Alexander } \\
(2010)\end{array}$ \\
\hline
\end{tabular}

\section{Considerações finais}

Apesar do BehavePlus ser uma ferramenta comumente utilizada pelas pessoas responsáveis pelo manejo do fogo, principalmente nos Estados Unidos, está claro que o software é uma ferramenta auxiliar e que nem todas as decisões devem ser tomadas apenas com base em suas simulações, já que é comum encontrar trabalhos na literatura que reportam discrepâncias entre os dados simulados e os dados obtidos em campo.

Os erros normalmente costumam ocorrer quando não se leva em conta a diversidade do material combustível, assumindo as condições como constantes, ou utilizando-se, sem uma boa base científica, de um dos 53 modelos padrão de material combustível. Ainda assim, modelos customizados, baseados em valores médios característicos da vegetação local, podem não ser eficientes, já que modelos matemáticos inseridos na base do BehavePlus, como o modelo de propagação de fogo de superfície de Rothermel (1972), foram desenvolvidos em laboratório e calibrados em condições homogêneas de material combustível, e sabe-se que durante a ocorrência de um incêndio em campo aberto o material combustível e as variáveis climáticas são muito heterogêneas. Caso o pesquisador venha a construir um modelo customizado, muito cuidado é necessário na caracterização da variável de entrada espessura do leito do material combustível, já que o modelo do fogo de superfície é bastante sensível para tal característica.

Destaca-se a necessidade do desenvolvimento e validação de novos modelos de materiais combustíveis que melhor descrevam o comportamento do fogo nas mais distintas formações vegetais. A validação de modelos customizados deve ser realizada através da correlação das simulações com os valores obtidos em situações reais. Quanto maior a existência de estudos envolvendo este software, mais rapidamente ele passará de uma ferramenta de pesquisa para uma ferramenta operacional.

Por fim, recomenda-se que os resultados simulados pelo BehavePlus sejam apenas avaliados por pessoas 
com experiência em pesquisa ou manejo do fogo e que saibam quando os dados gerados através das simulações são ou não condizentes com os dados obtidos na prática durante a ocorrência de fogo na vegetação.

\section{Agradecimentos}

À FAPITEC/SE pela bolsa de Doutorado concedida ao primeiro autor.

\section{Referências}

ANDRÉ, J. C. S.; VIEGAS, D. X. Modelos de propagação de fogos florestais: estado-da-arte para utilizadores. Parte II: modelos globais e sistemas informáticos. Silva Lusitana, Oeiras, v. 10, n. 2 , p. 217-233, 2002.

ANDREWS, P. L. BEHAVE: fire behavior prediction and fuel modeling system. Ogden: Unites States Department of Agriculture, Forest Service, 1986. 110 p. (General technical report INT, 194).

ANDREWS, P. L. BehavePlus fire modeling system, version 4.0: variables. Ogden: United States Department of Agriculture, Forest Service, 2008. 108 p. (General technical report RMRS-GTR, 213).

ANDREWS, P. L. BehavePlus fire modeling system, version 5.0: varibles. Ogden: United States Department of Agriculture, Forest Service, 2009. 111 p. (General technical report RMRS-GTR, 213).

ANDREWS, P. L. Do you BEHAVE? Application of the BehavePlus fire modeling system. In: FIRE BEHAVIOR AND FUELS CONFERENCE, 3. Proceedings... Alabama: International Association of Wildland Fire, 2010. 17 p.

ANDREWS, P, L.; QUEEN, L. P. Fire modeling and information system technology. International Journal of Wildland Fire, v. 10, n. 4 , p. $343-352,2001$.

ANDREWS, P. L.; BEVINS, C. D.; SELI, R. C. BehavePlus fire modeling system version 2.0 user's guide. Ogden: United States Department of Agriculture, Forest Service, 2003. 133 p. (General technical report RMRS-GTR, 106).

BARRETT, T. M.; JONES, J. G.; WAKIMOTO, E. R. H. Forest service spatial information use for planning prescribed fires. Western Journal of Applied Forestry, v. 15, n. 4, p. 200-207, 2000.

BEUTLING, A. Caracterização para modelagem de material combustível superficial em reflorestamento de Araucaria angustifolia (Bert.) O. Ktze. 2005. 113 f. Dissertação (Mestrado em Ciências Florestais) - Universidade Federal do Paraná, Curitiba.

BURGAN, R. E. Concepts and interpreted examples in advanced fuel modeling. Ogden: United States Department of Agriculture, Forest Service, 1987. (General technical report GTR-INT, 238).

BURGAN, R. E.; ROTHERMEL, R. C. BEHAVE: fire behavior prediction and fuel modeling system: fuel subsystem. Odgen: Intermountain Forest and Range Experiment Station, 1984. 126 p.

BYRAM, G. M. Combustion of forest fuels. In: DAVIS K. P. (Ed.). Forest fire control and use. New York: McGraw-Hill Book, 1959. p. 61-89.
CERAPIÁ, V. R. Predição do índice de risco de incêndio e modelagem computacional do comportamento do avanço da frente do fogo no Parque Nacional da Floresta da Tijuca. 2006. 197 f. Tese (Doutorado em Engenharia Civil) - Universidade Federal do Rio de Janeiro, Rio de Janeiro.

CRUZ, M. G.; ALEXANDER, M. E. Assessing crown fire potential in coniferous forests of western North America: a critique of current approaches and recent simulation studies. International Journal of Wildland Fire, v. 19, p. 377-398, 2010.

CRUZ, M. G.; FERNANDES, P. M. Development of fuel models for fire behavior prediction in maritime pine (Pinus pinaster Ait.) stands. International Journal of Wildland Fire, v.17, p. 194 - 204, 2008.

CURT, T.; DELCROS, P. Simulating fire ignition and initial propagation at road-forest interfaces. In: INTERNATIONAL WILDLAND FIRE CONFERENCE, 4., 2007. Proceedings... Sevilha: [s.n.], 2007. p. 13-17.

DIAMOND, J. M.; CALL, C. A.; DEVOE, N. Effects of targeted cattle grazing on fire behavior of cheatgrass-dominated rangeland in the northern Great Basin, USA. International Journal of Wildland Fire, v. 18, p. 944-950, 2009.

DIMITRAKOPOULOS, A. P. Mediterranean fuel models and potential fire behaviour in Greece. International Journal of Wildland Fire, v. 11, n. 2, p. 127-130, 2002.

FERNANDES, P. A. M. Desenvolvimento de relações preditivas para uso no planeamento de fogo controlado em povoamentos de Pinus pinaster Ait. 2002. 285 f. Tese (Doutorado em Ciências Agrárias) - Universidade de Trás-os-Montes e Alto Douro, Vila Real.

FERNANDES, P. A. M. Examining fuel treatment longevity through experimental and simulated surface fire behaviour: a maritime pine case study. Canadian Journal Forest Research, v. 39, p. 2529-2535, 2009.

FINNEY, M. A. An overview of FlamMap fire modeling capabilities. In: ANDREWS, P. L.; BUTLER, B. W. (Eds.) Fuels ManagementHow to Measure Success. Proceedings... Fort Collins, CO: U.S. Department of Agriculture, Forest Service, Rocky Mountain Research Station, 2006. p. 213 - 220.

FINNEY, M. A. FARSITE: fire area simulator: model development and evaluation. Ogden: United States Department of Agriculture, Forest Service, 2004. 47 p. (Research paper RMRS-RP, 4).

GILL, A. M. How fires affect biodiversity. In: Fire and Biodiversity: the effects and effectiveness of fire management. Canberra, ACT : Biodiversity Unit, Dept. of the Environment, Sport and Territories, 1996. (Biodiversity series. Paper number, 8).

GLITZENSTEIN, J. S. Fuels and fire behavior in chipped and unchipped plots: Implications for land management near the wildland/urban interface. Forest Ecology and Management, v. 236, n. 1, p. 18-29, 2006.

GOULD, J. S. Validation of the Rothermel fire spread model and related fuel parameters in grassland fuels. In: CHENEY, N. P.; GILL, A. M. (Eds.) Conference on Bushfire Modelling and Fire Danger Rating. Proceedings... CSIRO Canberra. 1991. p. 51-64. 
GRABNER, K.; DWYER, J.; CUTTER, B. Validation of behave fire behavior predictions in Oak Savannas using five fuel models. In: PALLARDY, S. G.; CECICH, R. A.; GARRETT, E. H.; JOHNSON, P. S. (Ed.). Proceedings... Columbia: United States Department of Agriculture, Forest Service, 1997. p. 202-215. (General technical report $\mathrm{NC}, 188$ ).

HOFFMANN, W. A.; JACONIS, S. Y.; MCKINLEY, K. L.; GEIGER, E. L.; GOTSCH, S. G.; FRANCO, A. C. Fuels or microclimate? Understanding the drivers of fire feedbacks at savanna-forest boundaries. Austral Ecology, v. 37, n. 6, p. 634-643, 2012.

HOOD, S. M.; MCHUGH, C. W.; RYAN, K. C.; REINHARDT, E.; SMITH, S. L. Evaluation of a post-fire tree mortality model for western USA conifers. International Journal of Wildland Fire, v. 16, n. 6, p. 679-689, 2007.

HOUGH, W. A.; ALBINI, F. A. Predicting fire behavior in Palmetto-Gallberry fuel complexes. North Caroline: United States Department of Agriculture, Forest Service, 1978. 44 p.

KEANE, R. E. Describing wildland surface fuel loading for fire management: a review of approaches, methods and systems. International Jounal of Wildland Fire, special issue, 2012.

McARThUR, A. G. Control burning in eucalypt forests. Commonwealth of Australia, Forestry and Timber Bureau Leaflet, n. 80, 1962, 31 p.

MISTRY, J.; BERARDI, A. Assessing fire potential in a Brazilian Savanna Nature Reserve1. Biotropica, v. 37, n. 3, p. 439-451, 2005.

MOHR, H. H.; WALDROP, T. A.; SIMON, D. M. Using BehavePlus for predicting fire behavior in Southern Appalachian hardwood stands subjected to fuel reduction treatments. In: CONNOR, K. F. (Ed.). 12th biennial southern silvicultural research conference. Proceedings... Asheville, NC: United States Department of Agriculture - Forest Service, Southern Research Station, 2004. p. 71-73. (Gen. Tech. Rep. SRS-71).

MOHR, H. H.; WALDROP, T. A.; RIDEOUT, S.; PHILLIPS, R. J.; FLINT, C. T. Effectiveness of fire and fire surrogate treatments for controlling wildfire behavior in Piedmont Forests: a simulation study. In: STANTURF, J. A. (Ed.). 14th biennial southern silvicultural research conference. Proceedings... Asheville, NC: United States Department of Agriculture - Forest Service, Southern Research Station, 2010. p. 565-567. (Gen. Tech. Rep. SRS-121).

ROTHERMEL, R. C.; RINEHARD, G. C. Field procedures for verification and adjustment of the fire behavior predictions. United States Department of Agriculture, Forest Service, 1983. 25 p. (General technical report INT, 142).

ROTHERMEL, R. C. A mathematical model for predicting fire spread in wildland fuels. Ogden: United States Department of Agriculture, Forest Service, 1972. 40 p. (Research Paper INT-115).
RYAN, K. C.; AMMAN, G. D. Interactions between fire-injured trees and insects in the Greater Yellowstone Area. In: DESPAIN, D. G. (Ed.). Plants and their environment. Washington, D.C.: USDI National Park Service, 1994. p. 89-101.

SANTOS, J. F.; SOARES, R. V.; BATISTA, A. C. Perfil dos incêndios florestais no Brasil em áreas protegidas no período de 1998 a 2002. Revista Floresta, Curitiba, v. 36, n. 1, p. 93-100, 2006.

SCOTT, J. H.; BURGAN, R. E. Standard fire behavior fuel models: a comprehensive set for use with Rothermel's surface fire spread model. Fort Collins, CO: United States Department of Agriculture, Forest Service, Rocky Mountain Research Station, 2005. 72 p. (General technical report. RMRS-GTR, 153)

SOARES, R. V.; BATISTA, A. C. Incêndios florestais: controle, efeitos e uso do fogo. Curitiba, 2007. 264 p.

STEPHENS, S. L.; WEISE, D. R.; FRY, D. L.; KEIFFER, R. J.; DAWSON, J.; KOO, E.; POTTS, J.; PAGNI, P. J. Measuring the rate of spread of chaparral prescribed fires in Northern California. Fire Ecology, v. 4, n. 1, p. 74-86, 2008.

VAN WAGNER. Conditions for the start and spread of crown fire. Canadian Journal of Forest Research. v. 7, p. 23-34, 1977.

VAN WAGTENDONK, J. W.; BOTTI, S. J. Modeling behavior of prescribed fires in Yosemite National Park. Journal of Forestry, v. 82, n. 6, p. 479-484, 1984.

VOLLMER, J. L. New Technology for Fuel Breaks and Green Strips in Urban Interface and Wildland Areas. In: BUTLER, B. W.; ALEXANDER, M. E. (Eds.) Eighth International Wildland Firefighter Safety Summit - Human Factors - 10 Years Later; Missoula, MT: The International Association of Wildland Fire, Hot Springs, SD, 2005. p. 1-7.

WAGTENDONK, J. W. V. Use of a deterministic fire growth model to test fuel treatments Sierra Nevada Ecosystem. California: University of California, Centers for Water and Wildland Resources, 1996. $13 \mathrm{p}$.

WELLS, G. The Rothermel Fire-Spread Model: still running like a champ. Fire Science Digest, v. 2, p. 1-12, 2008.

WHITE, B. L. A. Incêndios florestais no Parque Nacional Serra de Itabaiana - Sergipe. 2010. 142 f. Dissertação (Mestrado em Desenvolvimento e Meio Ambiente) - Universidade Federal de Sergipe, São Cristóvão. 
